University of Wollongong

Research Online

Faculty of Engineering and Information

Faculty of Engineering and Information

Sciences - Papers: Part B

Sciences

2019

Parameter optimization of adaptive flux-weakening strategy for permanentmagnet synchronous motor drives based on particle swarm algorithm

Wei Xu

Huazhong University of Science and Technology

Moustafa Magdi Ismail

Huazhong University of Science and Technology

Yi Liu

Huazhong University of Science and Technology, yiliu@uow.edu.au

Md Rabiul Islam

University of Wollongong, mrislam@uow.edu.au

Follow this and additional works at: https://ro.uow.edu.au/eispapers1

Part of the Engineering Commons, and the Science and Technology Studies Commons

Research Online is the open access institutional repository for the University of Wollongong. For further information contact the UOW Library: research-pubs@uow.edu.au 


\title{
Parameter optimization of adaptive flux-weakening strategy for permanent- magnet synchronous motor drives based on particle swarm algorithm
}

\begin{abstract}
Operating in the high-speed range is necessary for high-performance permanent-magnet synchronous motor (PMSM) drives. However, due to the back electromotive force effect, the PMSM is approaching the voltage limit at field decreasing scope. This paper presents a new flux-weakening scheme along with an improved vector control strategy to alleviate the influence of this problem. Control parameters of the antiwindup proportional and integral (AWPI) controller are optimized off-line in relying on an adaptive velocity particle swarm optimization (AVPSO) algorithm. The AVPSO algorithm considers the summation of AWPI measurement error which is the objective function of the optimization problem without knowing the transfer function of the plant. Hence, the tuned flux-weakening controller with a filter is used to set the flux level without saturating the current controllers. Meanwhile, the other controllers of inner and outer loops award a great dynamic and steady-state performance for the PMSM. In the proposed scheme, the flux-weakening control is not dependent on machine parameters that adapts the flux level automatically and provide a fast transition between the constant torque region and the field-weakening region. Effectiveness and advantages of the proposed scheme are presented in this paper through both simulation and experimental results.

\section{Disciplines}

Engineering | Science and Technology Studies

\section{Publication Details}

W. Xu, M. Magdi. Ismail, Y. Liu \& M. Islam, "Parameter optimization of adaptive flux-weakening strategy for permanent-magnet synchronous motor drives based on particle swarm algorithm," IEEE Transactions on Power Electronics, vol. 34, (12) pp. 12128-12140, 2019.
\end{abstract}




\title{
Parameter Optimization of Adaptive Flux-Weakening Strategy for Permanent-Magnet Synchronous Motor Drives Based on Particle Swarm Algorithm
}

\author{
Wei Xu, Senior Member, IEEE, Moustafa Magdi Ismail, Yi Liu, Member, IEEE, \\ and Md Rabiul Islam, Senior Member, IEEE
}

\begin{abstract}
Operating in the high-speed range is necessary for high-performance permanent magnet synchronous motor (PMSM) drives. However, due to the back electromotive force effect, the PMSM is approaching the voltage limit at field decreasing scope. This paper presents a new flux-weakening scheme along with an improved vector control strategy to alleviate the influence of this problem. Control parameters of the anti-windup proportional and integral (AWPI) controller are optimized off-line in relying on an adaptive velocity particle swarm optimization (AVPSO) algorithm. The AVPSO algorithm considers the summation of AWPI measurement error which is the objective function of the optimization problem without knowing the transfer function of the plant. Hence, the tuned fluxweakening controller with a filter is used to set the flux level without saturating the current controllers. Meanwhile, the other controllers of inner and outer loops award a great dynamic and steady-state performance for the PMSM. In the proposed scheme, the flux weakening control is not dependent on machine parameters which adapts the flux level automatically and provide a fast transition between the constant torque region and the field weakening region. Effectiveness and advantages of the proposed scheme are presented in this paper through both simulation and experimental results. ${ }^{1}$
\end{abstract}

Index Terms-- Surface mounted permanent magnet synchronous motor (SMPMSM), anti-windup proportional and integral (AWPI) controller, tuning method, adaptive velocity particle swarm optimization (AVPSO), flux weakening control.

\section{INTRODUCTION}

Permanent magnet synchronous motor (PMSM) applications tend to have a higher initial cost. Hence, they may offer a smaller size for more compact mechanical packages, desirable torque to inertia ratio, high reliability, and more controllability [1], [2]. Recently, the high-performance PMSM

Wei Xu, Moustafa Magdi Ismail, and Yi Liu (Corresponding Author) are with the State Key Laboratory of Advanced Electromagnetic Engineering and Technology, School of Electrical and Electronic Engineering, Huazhong University of Science and Technology, Wuhan, 430074, China. (E-mails: weixu@hust.edu.cn; mostafa.ismaiel@minia.edu.eg; liuyi82@hust.edu.cn)

Moustafa Magdi Ismail is also with the Electrical Engineering Department, Faculty of Engineering, Minia University, Minia, 61519, Egypt.

Md Rabiul Islam is with the School of Electrical, Computer and Telecommunications Engineering, University of Wollongong, New South Wales, 2522, Australia. (E-mail: mrislam@uow.edu.au).

This work has been partly supported by the National Natural Science Foundation of China (NSFC 51877093, 51707079 and 51807075) and National Key Research and Development Program of China (Project ID: 2018YFE0100200). drive system has been developed, which increases their reputation in electric vehicle applications [3-7]. In this application, instant response to the desired change, stability for the load variation, and minimizing the speed and torque ripple are necessary. For this reason, it is irresistible to work in the high-speed range.

In recent years, numerous methods have been developed for PMSM drive systems to extend the speed range [8-19]. In [9], a novel method of PMSM drive has been proposed to maximize the speed range. Ref. [9] presents a threedimensional finite element to create a gap between a stator and a rotor in an axial direction without moving the current vector. However, the above methods heavily depend on the no-load back-emf, which is necessary through computation of the linkage magnetic flux of stator windings and $d$-axis and $q$-axis inductance. The presented method in [12] uses the single linear multiple-input multiple output predictive controller to calculate the required flux-weakening $d$-axis current. Meanwhile, a new linearization approach is adopted to get the lower peak ripples of electrical current and torque. This approach tackles the strong coupled nonlinear mathematical model of interior buried PMSM. The control scheme of [17] modifies the field-weakening control of surface mounted permanent magnet synchronous motor (SMPMSM). The influence of the resistive voltage drop in the stator windings has not been considered in their studies. Nevertheless, the method presented in [17] is strongly dependent on motor parameters and operating conditions, but they guarantee good stability and transient responses. The proposed method in [11] depends on the measurement of inverter characteristics and the resistance of the used cable. This control method uses the voltage difference between the input and output of the inverter to modify the compensated $d$-axis current. Additionally, a proportional-integral (PI) controller uses the reference $q$-axis current to set the maximum torque per voltage. Therefore, the maximum torque can be accomplished at a high-speed range. The authors, in [16], have developed the flux-weakening control method, which determines the $d-q$ axes reference currents to drive a magnet-buried PMSM at any value of speed. This method minimizes the current magnitude to reach the reference torque considering the voltage and current limits and battery power. In [19], a single $q$-axis current regulator has been proposed to control the voltage angle. The advantages of this method are the stability in reaching the zero-load state and 
the fast-dynamic response of currents when current references are changed.

Various implementation methods of the nonlinear control theory have been used in the PMSM control system to improve the dynamic performances of critical issues such as torque disturbances and motor parameter variations [20-22]. A disturbance observer has been designed in [22] based on a nonsingular terminal sliding mode strategy to solve timevarying parameters and torque disturbances of the PMSM drive system. The system chattering can be compensated and reduced simultaneously, and it can achieve the smaller ripple in the presence of time-varying load. In [20], the authors estimate the disturbances and uncertainties of the current and speed loop based on a high-order sliding mode observer. Both the speed robustness and current tracking accuracy are increased by transmitting the estimated disturbances to a designed deadbeat-based predictive current controller.

This paper proposes an offline optimum tuning method for controllers that are constructing the suggested vector control strategy to utilize dc-link voltage as much as possible. The error measurement of the anti-windup PI controllers (AWPI) can be minimized to about zero depending on the adaptive velocity particle swarm optimization (AVPSO) algorithm. The optimization of the proposed fitness-function places emphasis on obtaining the best possible parameters for improving the stability of the system under load torque disturbances over a wide speed range. In the proposed control strategy, the field weakening compensator regulates the magnitude of the duty cycles to set the flux level without preventing the saturation of the current regulator. With the proposed control strategy, the SMPMSM performance is independent of parameter variations. The conventional flux weakening control (CFWC) has been presented in [18], which is a line modulation-based flux weakening control method. The performance of the proposed flux-weakening control (PFWC) is compared with the CFWC in this paper. Consequently, the main features of the PFWC can be summarized as follows:

1. The flux-weakening control loop of PFWC is supported by the low-pass filter that passes the signal with a lower frequency, thus raising and keeping the average of the $d$-axis reference current from falling suddenly. In contrast, the CFWC misses the filter causing the lower average of the $d$ axis reference current. The PFWC strategy is applicable to the interior PMSM because the proposed algorithm has no dependence on the structure difference between the surface magnets and embedded magnets. Taking into consideration, the parameters of the low-pass filter should be convenient with the parameters of the interior-magnet motor.

2. There is a primary difference between PFWC and CFWC in the structure of the PI controller, where the PI controllers of PFWC are supported by an anti-windup structure that affects positively in the transient period. Table I describes the main differences between the CFWC and the PFWC according to the analysis above.

This paper is systematized as follows. Section II represents the system description and model. Section III also introduces the PFWC and limitations of voltage and current. Moreover, this section presents the CFWC method. Additionally, Section IV presents the recommended off-line tuning method of a PI controller and the implementation of AVPSO algorithm. Afterwards, the proposed methods are numerically simulated in Section V, and verified by experimental results in Section VI. Finally, the conclusions are drawn in Section VII.

\section{SYSTEM MODELING}

Fig. 1 presents the basic block diagram of the surface mounted PMSM drive used in this paper for analysis. In this figure, the modified vector control drive commands the SMPMSM through a space vector PWM (SVPWM) based two-level voltage source inverter (VSI). The counting mechanical position and the measured phases currents are used as the control inputs. Moreover, the measured dc link voltage is used to calculate the output references of the duty cycles of the current regulators and to determine the onset point of the flux weakening. Considering that all the lowercase symbols are used to introduce instantaneous values and the upper case standing for the steady state. In SMPMSM with more than one magnet, the differential equations are defined as

$$
\begin{gathered}
v_{q s}=R_{s} i_{q s}+\frac{d}{d t} \lambda_{q s}+\omega_{r}\left(L_{s} i_{d s}+\lambda_{m}\right) \\
v_{d s}=R_{s} i_{d s}+\frac{d}{d t} \lambda_{d s}-\omega_{r} L_{s} i_{q s}
\end{gathered}
$$

where $\lambda_{m}$ is the flux linkage due to the rotor magnets linking the stator, $L_{s}$ is the stator inductance, $\omega_{r}$ is the electrical velocity of the rotor, and $R s$ is the stator resistance. Additionally, $v_{d s}$ and $v_{q s}$ are $d-q$ axes voltages, $\lambda_{d s}$ and $\lambda_{q s}$ are $d-q$ axes fluxes, $i_{q s}$ and $i_{d s}$ are $d-q$ axes stator currents, respectively.

Moreover, the mechanical equation of the motor can be represented as

$$
J \frac{d \omega_{m}}{d t}=T_{e}-T_{L}-B \omega_{m}
$$

where $\omega_{m}$ is the mechanical velocity of the rotor, $T_{L}$ is the load torque, $T_{e}$ is the electromagnetic torque, $B$ is the viscous frictions coefficient, and $J$ is the inertia of the shaft. Furthermore, the electromagnetic torque in a steady state can be given by

$$
T_{e}=\frac{3}{2} n_{p} \lambda_{m} i_{q s}
$$

where $n_{p}$ is the number of pair pole. The average model of VSI in $d-q$ axes can be expressed as

$$
\left\{\begin{array}{l}
\frac{d i_{d q s}}{d t}=\frac{1}{3 L_{s}} d_{d q} V_{d c}-\frac{\omega_{r}}{3 L_{s}} \lambda_{d q s}+\left[\begin{array}{cc}
\frac{-R_{s}}{L_{s}} & \omega_{r} \\
-\omega_{r} & \frac{-R_{s}}{L_{s}}
\end{array}\right] i_{d q s} \\
I_{d c}=C \frac{d V_{d c}}{d t}+\frac{1}{3} d_{d q}^{T} i_{d q s}
\end{array}\right.
$$


TABLE I

DIFFERENCES BETWEEN PFWC AND CFWC

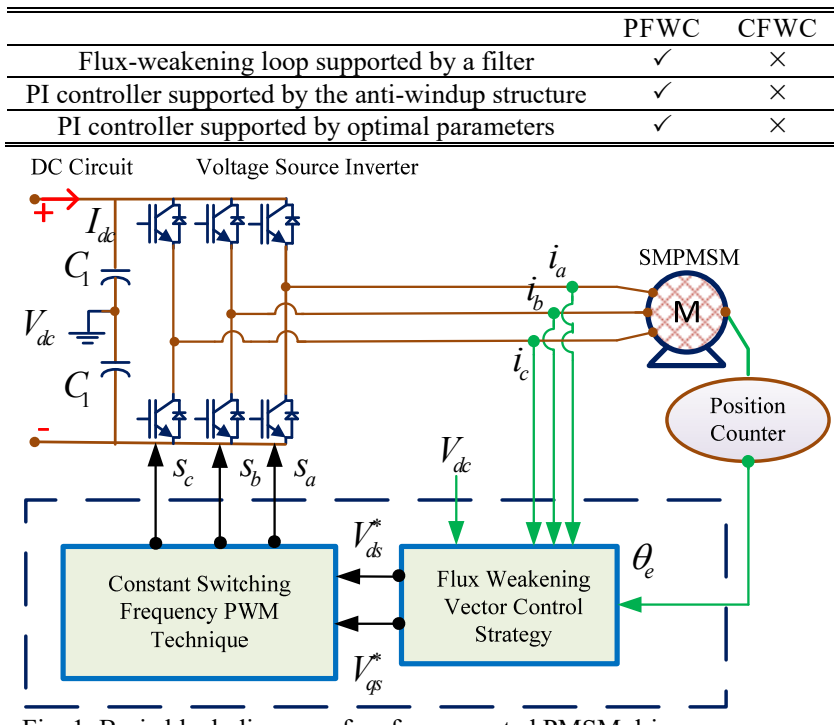

$\overline{\text { Fig. } 1 . ~} \overline{\text { Basic }}$ block diagram of surface mounted PMSM drive.

where $d_{d}$ and $d_{q}$ are $d$ - $q$ axes duty cycles, $V_{d c}$ is dc-link voltage, $I_{d c}$ is dc-link circuit current, and $C$ is the dc-link equivalent capacitor. In addition, $i_{d q s}, d_{d q}$, and $\lambda_{d q s}$ can be considered as $\left[\begin{array}{l}i_{d s} \\ i_{q s}\end{array}\right],\left[\begin{array}{l}d_{d} \\ d_{q}\end{array}\right],\left[\begin{array}{l}\lambda_{d s} \\ \lambda_{q s}\end{array}\right]$, respectively.

The voltage vector magnitude $(\rho)$ of VSI is indicating the region where the SMPMSM is working and can be determined by

$$
\rho=\left(\sqrt{v_{\alpha}^{2}+v_{\beta}^{2}}\right) /\left(V_{d c} / \sqrt{3}\right)
$$

where $\rho$ is the per-unit value of the voltage vector magnitude while the base value is the maximum voltage that the inverter can supply to the motor $\left(V_{d c} / \sqrt{3}\right), v_{\alpha}$ and $v_{\beta}$ are the $\alpha$ and $\beta$ components of the voltage vector obtained by the reverse Park transformation with the inputs $v_{q s}$ and $v_{d s}$ of the VSI. As the main flux weakening problem, an increase in motor rotational speed comes with a proportional increase in the electromotive

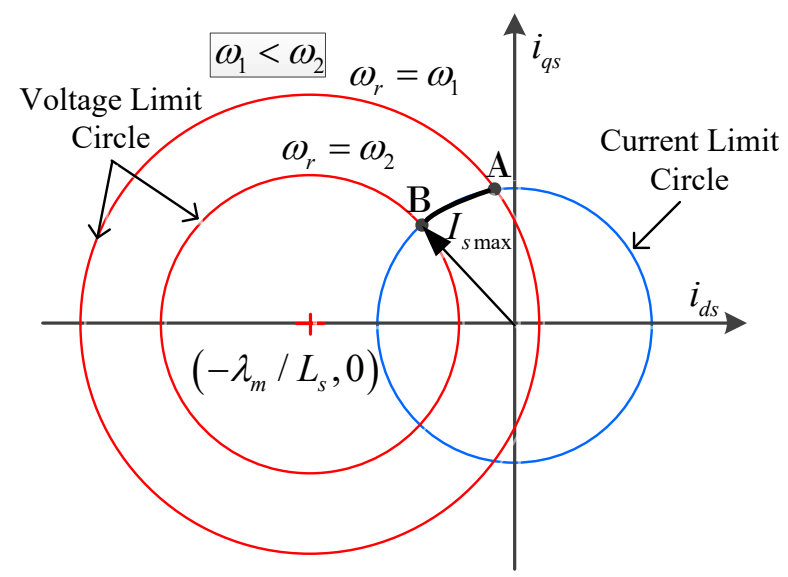

Fig. 2. Voltage and current limit diagram for the maximum torque per current of SMPMSM in $i_{\mathrm{ds}}-i_{\mathrm{qs}}$ plane. force term of (1). Therefore, the voltage is not efficient to control the current, and the torque becomes highly distorted. As a result, it is necessary to feed negative $d$-axis current for the extension of the motor speed range.

\section{FLUX-WEAKENING SCHEMES}

\section{A. Operating Limits in Flux-Weakening Scope}

As mentioned before, the space vector PWM technique switches the VSI. A voltage vector under the flux weakening region was laying on the boundary of the hexagon, which limits the voltage identifying the maximum supply voltage $\left(V_{s m \text { ax }}=V_{d c} / \sqrt{3}\right)$ [11]. Moreover, both converter's power rating and motor's thermal rating are used to calculate the maximum current $I_{\text {smax }}$. Accordingly, the voltage and the current limits of the motor can be expressed as

$$
\begin{aligned}
& V_{d s}^{2}+V_{q s}^{2} \leq V_{s m \text { ax }}^{2} \\
& I_{d s}^{2}+I_{q s}^{2} \leq I_{s \max }^{2} .
\end{aligned}
$$

By omitting the resistance term in the high rotating speed range, the equations (1), (2), and (7) can be modified as

$$
I_{q s}^{2}+\left(I_{d s}+\lambda_{m} / L_{s}\right)^{2} \leq V_{s \max }^{2} /\left(\omega_{r} L_{s}\right)^{2} .
$$

The equation (9) expresses the circle of a motor voltage limit with a radius of $V_{s m \text { ax }} /\left(\omega_{r} L_{s}\right)$ and centered at $\left(-\lambda_{m} / L_{s}, 0\right)$. Fig. 2 shows the circles with a variable radius voltage limit; circle intersects with the constant radius current limit circle. As speed increases, the operating point moves from A to B. Consequently, the $q$-axis current point of the maximum torque is the cross point between the two circles, which can be defined as

$$
I_{q s}=\left(L_{s} / 2 \lambda_{m}\right) \sqrt{\left(2 \lambda_{m} I_{s \max } / L_{s}\right)^{2}-\left(\left(\lambda_{m} / L_{s}\right)^{2}-\left(V_{s \max } /\left(\omega_{r} L_{s}\right)\right)^{2}+I_{s \max }^{2}\right)}(10)
$$

And then, the flux weakening current function of the speed can be expressed as

$$
I_{d s}=-\sqrt{I_{s \max }^{2}-I_{q s}^{2}} .
$$

\section{B. Proposed Flux-Weakening Strategy}

Fig. 3 describes the block diagram of the proposed flux weakening control strategy based on the AWPI structure. In this structure, the integrator parameter is multiplying with the error of the PI controller, which is subtracting with the value of $\Delta \mathrm{y}^{*}$ times by $K_{a w}$ as clarified in Fig. 3(a), where the symbol of " $\Delta$ " intends the difference between the compensated value of the AWPI controller and saturated value. Besides, the quantities with " $*$ " are the reference values and the symbol of "•" indicates the differential value. Also, $K_{a w}$ is the antiwindup variable which can be calculated as the ratio between the integral parameter to the proportional parameter $\left(K_{I} / K_{P}\right)$, and $\phi^{\bullet}$ is the AWPI controller error. A feature of the coordinated structure, the anti-windup structure (AWS) decreases the error of integral value to reduce the overshoot effect of saturation. Further, Fig. 3(c) presents the block diagram of the proposed control strategy. For improving the current response, the decoupling terms of (1) and (2) are 
removed from the $d-q$ axes stator voltages references as follows:

$$
\left\{\begin{array}{l}
v_{d_{\text {decoupling }}}=\quad-L_{s} \omega_{r} i_{q s} \\
v_{q_{\text {decooppling }}}=L_{s} \omega_{r} i_{d s}+\omega_{r} \lambda_{m}
\end{array} .\right.
$$

The error equations of the current AWPI controllers can be defined as

$$
\begin{gathered}
\phi_{1}=\frac{v_{q s}^{*}}{K_{P-q}}-\frac{K_{I-q}}{K_{P-q}} \phi_{1}+\int K_{a w-q}^{2} \Delta d_{q}^{*}-\frac{L_{s} n_{p}}{K_{P-q}} i_{d s} \omega_{m}-\frac{\lambda_{m} n_{p}}{K_{P-q}} \omega_{m}-i_{q s}^{*}+i_{q s} \\
\phi_{2}^{\square}=\frac{v_{d s}^{*}}{K_{P-d}}-\frac{K_{I-d}}{K_{P-d}} \phi_{2}+\int K_{a w-d}^{2} \Delta d_{d}^{*}+\frac{L_{s} n_{p}}{K_{P-d}} i_{q s} \omega_{m}-i_{d s}^{*}+i_{d s}
\end{gathered}
$$

where $K_{P-q}, K_{I-q}, K_{P-d}$, and $K_{I-d}$ are proportional and integral gains of the $q-d$ axes current controllers, $K_{a w-q}$ and $K_{a w-d}$ are the ratios between the integral gain to the proportional gain of the $q-d$ axes current controllers, $\phi_{1}$ and $\phi_{2}$ are the integrations of the error of the $q-d$ axes current controllers, $\phi_{1}^{\square}$ and $\phi_{2}^{\square}$ are the errors of the $q-d$ axes current controllers, respectively.
Furthermore, the error equation of speed AWPI controller can be described as

$$
\phi_{3}^{\natural}=\frac{i_{q s}^{*}}{K_{P-s}}-\frac{K_{I-s}}{K_{P-s}} \phi_{3}+\int K_{a w-s}^{2} \Delta i_{q s}^{*}-\omega_{m}^{*}+\omega_{m}
$$

where $K_{P-s}$ and $K_{I-s}$ are proportional and integral gains of the speed controller, respectively. $K_{a w-s}$ is the ratio between $K_{I-s}$ to $K_{P-s}$ of the speed controller, $\phi_{3}$ is the error of the speed controller, and $\phi_{3}$ is the integration of the error of the speed controller.

The $q$-axis current maximum limit $\left(i_{q s \max }^{*}\right)$ generating the torque decreases with the increase of the absolute value of $d$ axis reference current which presenting as

$$
i_{q s \max }^{*}=\sqrt{I_{s \max }^{2}-i_{d s}^{* 2}} .
$$

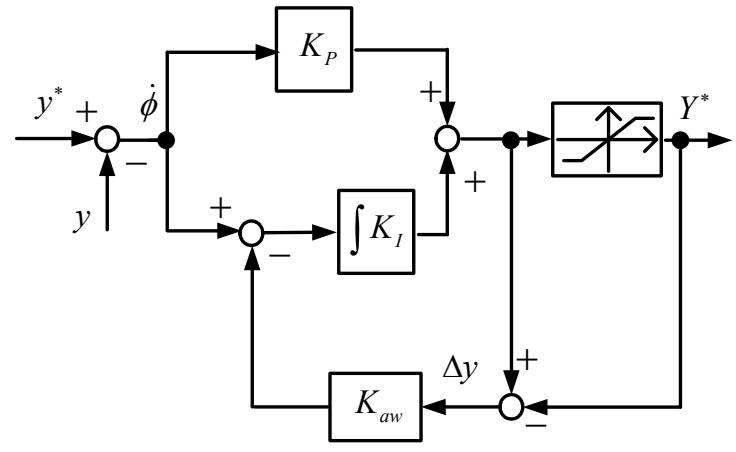

(a)

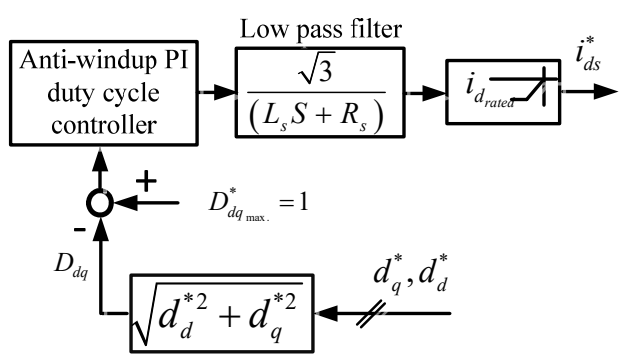

(b)

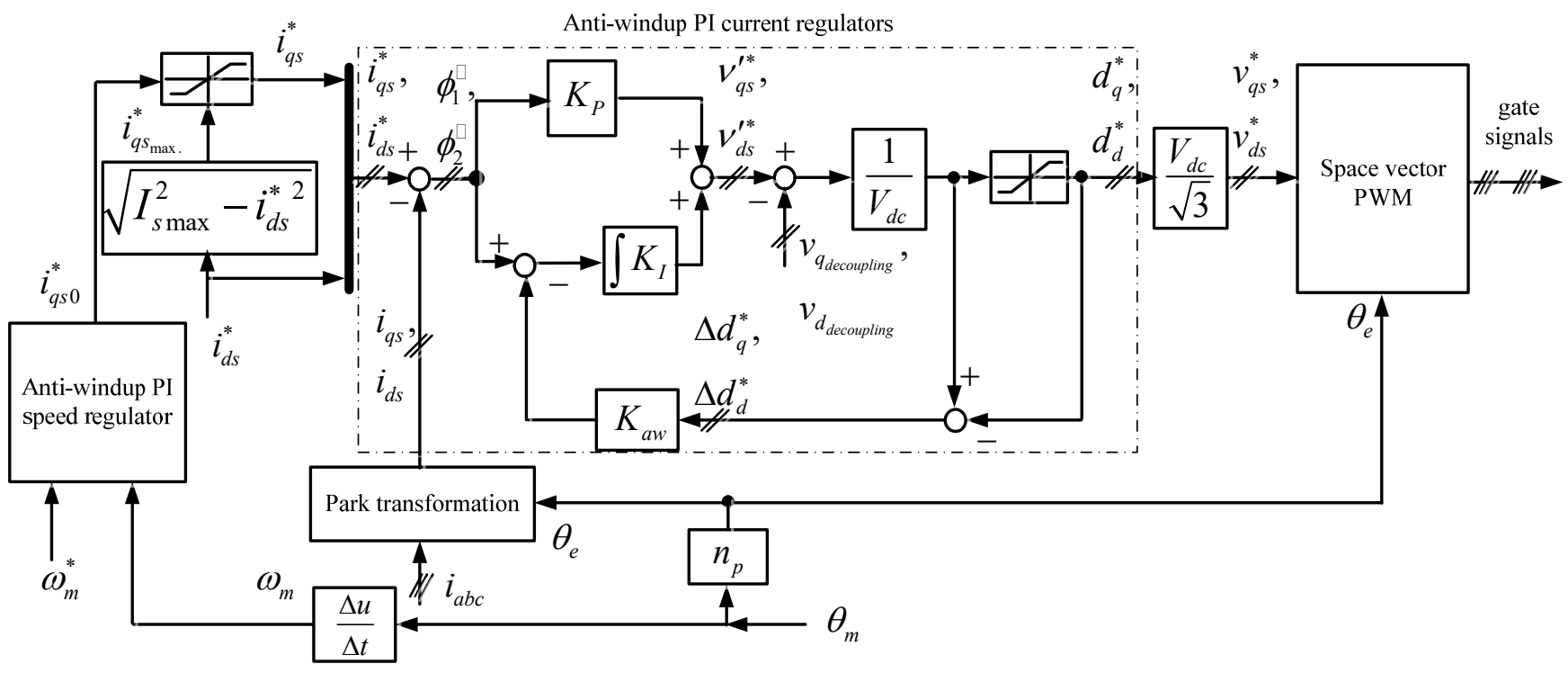

(c)

Fig. 3. Proposed flux weakening scheme, where (a) Structure of anti-windup PI controller, (b) flux weakening vector control loop, and (c) modified vector control. 
Therefore, the $d$-axis current reference should be dejected as much as possible to boost the torque.

The main idea of the PFWC part as shown in Fig. 3(b) is the employment of the magnitude of the compensated duty cycles $\left(D_{d q}\right)$ to determine the outbreak of the decreased field. Even if the dc link voltage drops suddenly, the duty cycles feedback can adjust the flux level freely. Showing appreciation for this outer PFWC loop, the mission accomplishes automatically despite a motor parameters variation or a load disturbance. In other words, as the motor speed is getting higher, the performance of the current controllers is getting lower because the compensated voltages are reaching the maximum voltage limit.

In the flux-weakening region, if the magnitude of the compensated duty cycles exceeds the reference limit, then the controller senses the error of the duty cycles reflecting the $d$ axis current negatively to prevent the expected saturation for the current controller. Moreover, the outer loop is activated when $D_{d q}$ is equal or higher than $D_{d q \max }^{*}=1$, otherwise $i^{*}{ }_{d s}=0$. Fig. 3 (c) illustrates how to calculate the $D_{d q}$ that can be derived as

$$
\left\{\begin{array}{l}
d_{q}^{*}=\left(v_{q s}^{\prime *}-v_{q_{d c c o p p l i n g}}\right) / V_{d c},-1 \leq d_{q}^{*} \leq 1 \\
d_{d}^{*}=\left(v_{d s}^{\prime *}-v_{d_{d e c o p p l i n g}}\right) / V_{d c},-1 \leq d_{d}^{*} \leq 1 \\
D_{d q}=\sqrt{d_{d}^{* 2}+d_{q}^{* 2}}, D_{d q} \in[0, \sqrt{2}]
\end{array}\right.
$$

where $v_{q s}^{\prime *}$ and $v_{d s}^{\prime *}$ are the output voltages of the $q$ - $d$ axes the current regulators, $d^{*}{ }_{q}$ and $d^{*}{ }_{d}$ are the compensated duty cycles of the $q-d$ axes current regulators, respectively. Finally, the error equation of PFWC loop can be represented by

$$
\phi_{4}^{\square}=\frac{i_{d s}^{*}}{K_{P-F W}}-\frac{K_{I-F W}}{K_{P-F W}} \phi_{4}+\int K_{a w-F W}^{2} \Delta i_{d s}^{*}-D_{d q \max }^{*}+D_{d q}
$$

where $K_{P-F W}$ and $K_{I-F W}$ are the proportional and integral gains of the duty cycle controller, respectively. $K_{a w-F W}$ is the ratio between $K_{I-F W}$ to $K_{P-F W}$ of the duty cycle controller, $\phi_{4}^{\square}$ is the error of the duty cycle controller, and $\phi_{4}$ is the integration of the error of duty cycle controller.

\section{Conventional Flux-Weakening Strategy}

Fig. 4 shows the block diagram of the CFWC system of the SMPMSM [18]. As indicated in this figure, the negative $d$-axis current is produced using the line-modulation loop enabling the SMPMSM to operate in the flux-weakening region. The maximum line modulation ratio is defined as

$$
\left\{\begin{array}{l}
m_{\text {max }}=\delta_{\text {max }}-\delta_{\text {min }} \\
\delta_{\text {max }}=\max \left\{\delta_{a}, \delta_{b}, \delta_{c}\right\} \\
\delta_{\text {min }}=\min \left\{\delta_{a}, \delta_{b}, \delta_{c}\right\}
\end{array}\right.
$$

where $m_{\max }$ is the maximum line-modulation-ratio, $\delta_{\max }$ and $\delta_{\min }$ are the maximum and minimum duty cycles, $\delta_{a}, \delta_{b}$, and $\delta_{c}$ are the inverter duty cycles of leg-1, leg-2 and leg-3, respectively.

Besides, $\delta_{a}$ and $\delta_{b}$ can be defined as

$$
\left\{\begin{array}{l}
m_{a c}=u_{a c}^{*} / V_{d c} \\
m_{b c}=u_{b c}^{*} / V_{d c}
\end{array}\right.
$$

$$
\left\{\begin{array}{l}
\delta_{a}=m_{a c}+\delta_{c} \\
\delta_{b}=m_{b c}+\delta_{c}
\end{array}\right.
$$

where $u_{a c}^{*}$ and $u_{b c}^{*}$ are the reference line voltage determining by inverse Park transformation of $v_{q s}^{*}$ and $v_{d s}^{*}, m_{a c}$ and $m_{b c}$ are the line-modulation-ratios, respectively.

In order to calculate $\delta_{c}$, the median value of the duty cycle of leg- 3 can be defined as

$$
\delta_{c}=\frac{\delta_{c_{-} \min }+\delta_{c_{-} \max }}{2}
$$

where $\delta_{\mathrm{c}_{-} \max }$ and $\delta_{\mathrm{C}_{-} \min }$ are maximum and minimum values of the phase-c-based duty cycle, respectively. More details about the calculation method of $\delta_{c}$ can be found in [18]. Moreover, the line modulation inverter technique of CFWC is used instead of SVPWM to generate the gate signals [23]. The reference value of $d$-axis current is zero except if $m_{\max } \geq 1$ the difference between $m_{\max }^{*}$ and $m_{\max }$ produces a negative reference current, where $m_{\max }^{*}$ is the reference maximum linemodulation-ratio. Meanwhile, the reference value of $q$-axis current is saturated as (16).

\section{TUNING METHOdOLOGY AND IMPLEMENTATION OF PROPOSED PARTICLE SWARM OPTIMIZATION ALGORITHM}

\section{A. Proposed Tuning Method}

Determination of the optimal control parameters of the PFWC strategy is essential to ensure the effectiveness of the system stability. This paper introduces a tuning method which is independent to the transfer function of the plant. However, the parameters determine the minimum value of the equilibrium point term $\left(\vec{f}\left(\vec{x}_{0}, \vec{u}_{0}\right)\right)$ of Taylor series are the optimal parameters. Equation (23) defines Taylor series expansion as

$$
\begin{aligned}
& \vec{f}(\vec{x}, \vec{u}) \cong \vec{f}\left(\vec{x}_{0}, \vec{u}_{0}\right)+\frac{\partial \vec{f}\left(\vec{x}_{0}, \vec{u}_{0}\right)}{\partial \vec{x}}\left(\vec{x}-\vec{x}_{0}\right)+\frac{\partial \vec{f}\left(\vec{x}_{0}, \vec{u}_{0}\right)}{\partial \vec{u}}\left(\vec{u}-\vec{u}_{0}\right)+ \\
& \frac{1}{2 !}\left[\frac{\partial^{2} \vec{f}\left(\vec{x}_{0}, \vec{u}_{0}\right)}{\partial \vec{x}^{2}}\left(\vec{x}-\vec{x}_{0}\right)^{2}+\frac{\partial^{2} \vec{f}\left(\vec{x}_{0}, \vec{u}_{0}\right)}{\partial \vec{x} \partial \vec{u}}\left(\vec{x}-\vec{x}_{0}\right)\left(\vec{u}-\vec{u}_{0}\right)+\frac{\partial^{2} \vec{f}\left(\vec{x}_{0}, \vec{u}_{0}\right)}{\partial \vec{u}^{2}}\left(\vec{u}-\vec{u}_{0}\right)^{2}\right] \\
& +\ldots
\end{aligned}
$$

where the subscript " 0 " indicates the equilibrium point value. The performance of the PI controller highly depends on the selection of the equilibrium point in the flux weakening region. Hence, the equilibrium point term $\left(\vec{f}\left(\vec{x}_{0}, \vec{u}_{0}\right)\right)$ of PFWC strategy can be calculated from (1)-(3), (13)-(15) and (18) as (24).

The proposed fitness function can be redefined as

$$
\text { Minimize }\left\{\sum_{j=1}^{4} \phi_{j}^{\square}\right\} \text {. }
$$

For this purpose, the proposed AVPSO algorithm [24] is applied to minimize the fitness function to zero by finding the optimal gains of the proportional and integral. 


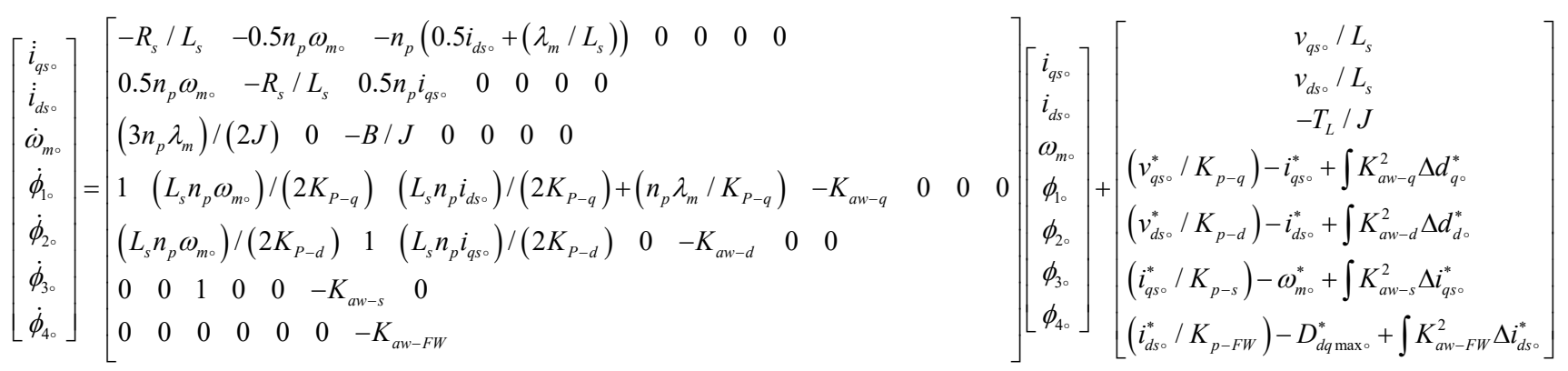

B. Implementation of the Proposed Adaptive Velocity Particle Swarm Algorithm

The particle swarm optimization (PSO) algorithm starts by generating the initial particle position vectors $\left(\hat{p}_{n}\right)$ where $n^{\text {th }}$ indicates the particle number and then assigning them initial velocities $\left(\hat{v}_{n}\right)$ and initial best local location $\left(\hat{b}_{n}=\hat{p}_{n}\right)$. In this

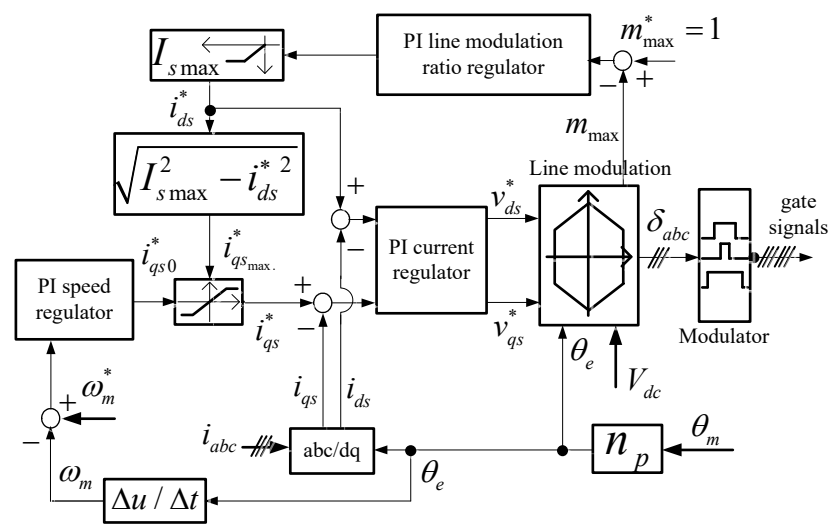

Fig. 4. Conventional flux weakening control method.

optimization, the vector length of $n^{\text {th }}$ particle equals 8 which is the number of controller parameters and can be defined as

$$
\left\{\begin{array}{l}
\hat{p}_{n}(1 \times 8)=\left[K_{I-q}, K_{P-q}, K_{I-d}, K_{P-d}, K_{I-s}, K_{P-s}, K_{I-F W}, K_{P-F W}\right] \\
n=[1: N]
\end{array}\right.
$$

where $N$ denotes the swarm size. The PSO evaluates the proposed fitness function for each particle position and then determines the evaluation vector of $n^{\text {th }}$ particle location $\left(\overrightarrow{\vec{g}}_{n}\right)$ that involving the global minimum solution $\left(g_{\text {best }}\right)$ and its corresponding to the optimal particle position $\left(p_{\text {global }}\right)$. After this initialization step, the PSO would implement a finite loop to optimize the particles locations. The optimization of particles locations depends on the proposed adaptive velocity as

$$
\left\{\begin{array}{l}
\widehat{V}_{n}=\omega_{A} \widehat{v}_{n}+c_{1} r_{1}\left(\hat{b}_{n}-\hat{p}_{n}\right)+c_{2} r_{2}\left(p_{\text {global }}-\hat{p}_{n}\right) \\
\omega_{A}=(g / G)\left(\sum_{1}^{L_{p}}\left|p_{\text {global }}-\widehat{b}_{n}\right| / L_{p}\right)
\end{array}\right.
$$

where $\omega_{A}$ is the weight factor, $L_{p}$ is the length of one particle, $c_{1}$ and $c_{2}$ are the acceleration coefficients and can have a value of 2, $r_{1}$ and $r_{2}$ are the positive random numbers less than or equal to one, respectively. Based on (27), the AVPSO updates the particle position as follow:

$$
\hat{P}_{n}=\hat{V}_{n}+\hat{p}_{n}
$$

where $\hat{V}_{n}$ is the $n^{\text {th }}$ updated particle velocity, and $\hat{P}_{n}$ the $n^{\text {th }}$ updated particle location, respectively. The stopping criterion of this loop is the continuity of the global best solution without change for more than 12 iterations, or the counter reaches one hundred iterations.

Focusing on the AVPSO algorithm against the proposed objective function, the evaluation procedure works in sight of knowing all fitness function variables. Consequently, the evaluation step faces a problem namely coefficients absent regarding $\phi_{1 \circ}, \phi_{2 \circ}, \phi_{3 \circ}, \phi_{4 \circ}, i_{q s \circ}^{*}$, and $i_{d s \circ}^{*}$. Therefore, it is necessary to call a separate AVPSO algorithm for each time during the evaluation of (25). In this interior optimization problem, the vector length of the particle equals 6 that can be defined as

$$
\left\{\begin{array}{l}
\tilde{p}_{k}(1 \times 6)=\left[\phi_{1 \circ}, \phi_{2 \circ}, \phi_{3 \circ}, \phi_{4 \circ}, i_{q s o}^{*}, i_{d s \circ}^{*}\right] \\
k=[1: 200]
\end{array}\right.
$$

where $\tilde{p}_{k}$ is the $k^{\text {th }}$ particle location of the internal AVPSO algorithm. In addition, the internal PSO algorithm has the same equations for updating the velocity and position as the outer AVPSO algorithm. Besides, $\tilde{v}_{k}$ indicates the $k^{\text {th }}$ particle velocity, $\tilde{b}_{k}$ the best $k^{\text {th }}$ local particle location, $p_{\text {best }}$ the global best location that corresponding to $k^{\text {th }}$ particle of the minimum evaluation, $\overrightarrow{\tilde{g}}_{k}$ the evaluation vector of the $k^{\text {th }}$ particle position, $g_{\text {best }}$ the minimum value for $\overrightarrow{\tilde{g}}_{k}, \tilde{V}_{k}$ the $k^{\text {th }}$ updated particle velocity, and $\tilde{P}_{k}$ the $k^{\text {th }}$ updated particle location, respectively. Finally, the internal PSO algorithm evaluates the proposed fitness function under the sight of the updated particle position $\left(\widehat{P}_{n}\right)$ of the outer PSO algorithm. Meanwhile, the outer PSO algorithm explores a lower value than that obtained in previous iterations. Figs. 5 and 6 present the flowcharts of the outer AVPSO algorithm that is used to optimize the controller parameters, and the interior AVPSO algorithm that is 
employed to define the missing variables for evaluating the proposed fitness function, respectively.

\section{Simulation Results}

To evaluate the performance of the proposed SMPMSM drive system a model is developed in the MATLAB/Simulink software environment. The main parameters of the motor are listed in Table II. A simulation block is designed to find the optimal gains of AWPI controllers in the proposed control strategy by using the proposed tuning method. The optimization problem of (25) is designed based on the proposed optimization algorithm with the population size of 50 and the generation number of 100. In Fig. 7, the optimization algorithm achieves the minimum error of about $1.10134 \mathrm{e}-13$ standing for the optimal tuning at 39 iterations. For this purpose, it decided to stop near 51 generation. Moreover, Table III presents the optimal parameters obtained by using the proposed off-line optimization method. Fig. 8 shows the frequency domain analysis of the control system. As presented in Fig. 8(a), the open loop bode diagram of the

TABLE II

IDENTIFICATION PARAMETERS OF SMPMSM MOTOR

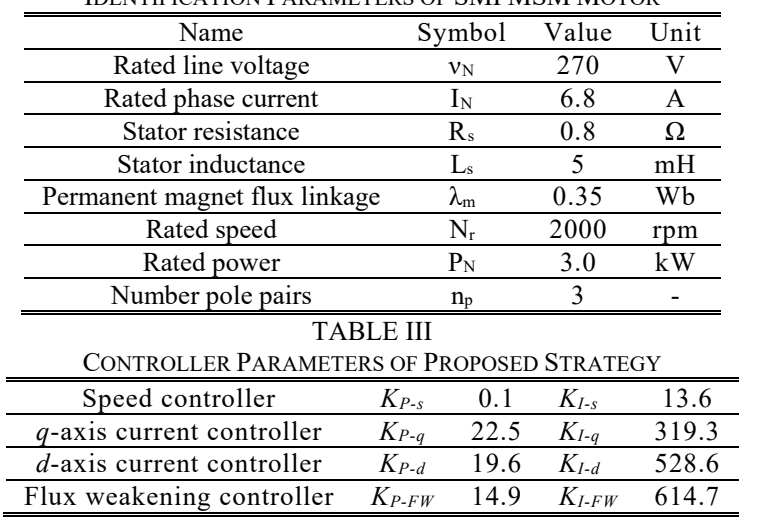

speed controller indicates the minimum stability of phase margin of about 112 degrees at a crossover frequency of $0.0387 \mathrm{kHz}$. The peak gain is $484 \mathrm{~dB}$ at the frequency of $1.59 \mathrm{e}-24 \mathrm{kHz}$. In the similar process, Fig.8(b) exhibits the open loop bode diagram of the current controller indicating the minimum stability of gain margin of about $-324 \mathrm{~dB}$ and a phase margin of about 95.7 degrees at the crossover frequency of $0.647 \mathrm{kHz}$. Moreover, the peak gain also is $436 \mathrm{~dB}$ at the frequency of $1.59 \mathrm{e}-24 \mathrm{kHz}$.

The PWM inverter has a constant switching frequency of 5 $\mathrm{kHz}$ with a dc-bus voltage of $400 \mathrm{~V}$. Fig. 9 illustrates the performance of PFWC and CFWC when the motor is controlled to run at the flux-weakening region under the desired speed of $2300 \mathrm{rpm}$ with an initial load reducing from $8.5 \mathrm{Nm}$ to half at $2 \mathrm{~s}$. Further, the simulation result of the PFWC algorithm with the standard PI controller structure (SPIS) also is presented in Fig. 9 to verify the effectiveness of the AWPI structure. As shown in Fig. 9(a), the PFWC algorithm is better than the CFWC algorithm in terms of the speed overshoot and the steady-state error. The PFWC algorithm with both controller structures has no steady-state error, while the average value of the steady-state error of the CFWC algorithm is $2.1 \%$ and decreasing to about $1 \%$ after load drop. Additionally, the speed overshoots at the motor starting and the load drop periods of the PFWC algorithm with an AWS are $3.5 \%$ and $6 \%$, and the counterparts of these periods for the CFWC algorithm are $6.5 \%$ and $10.5 \%$, respectively.

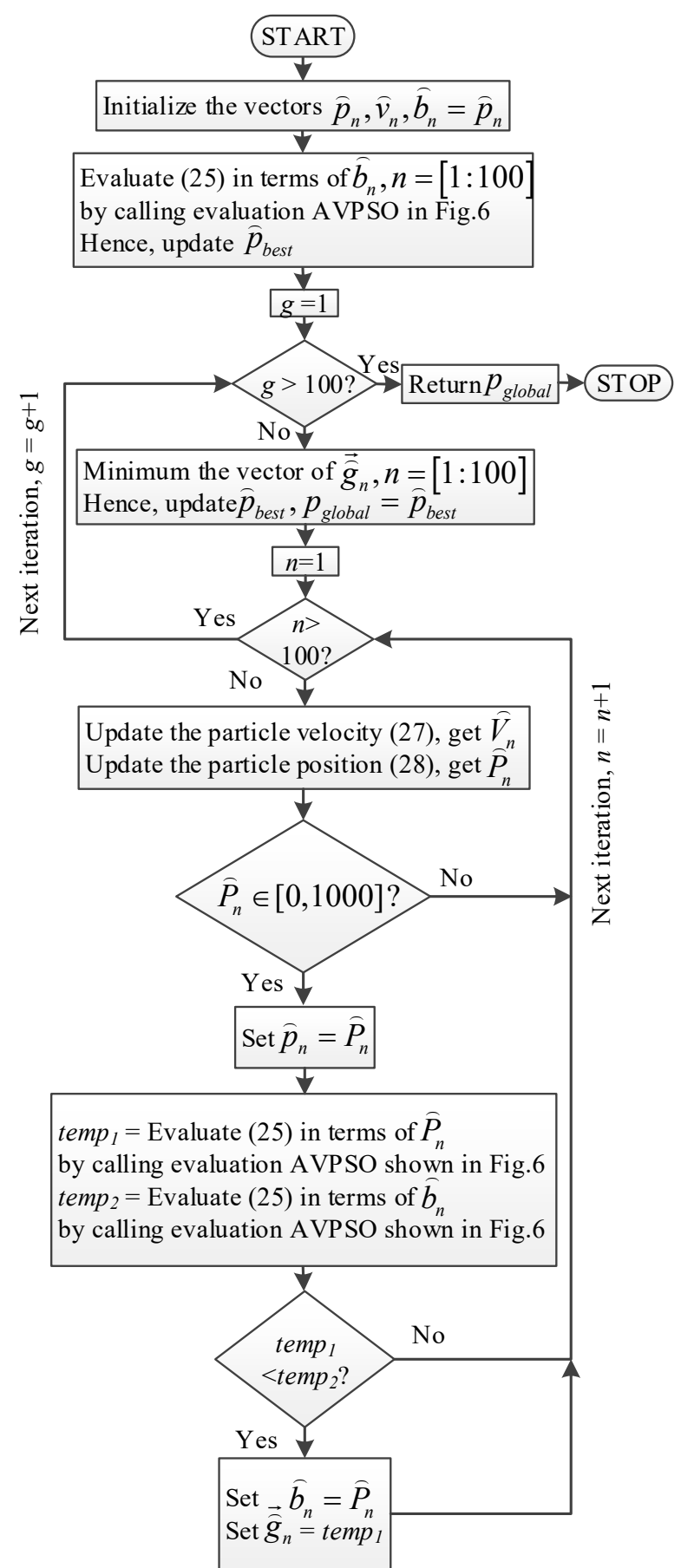

Fig. 5. Flowchart of the proposed algorithm for optimizing the controller parameters. 


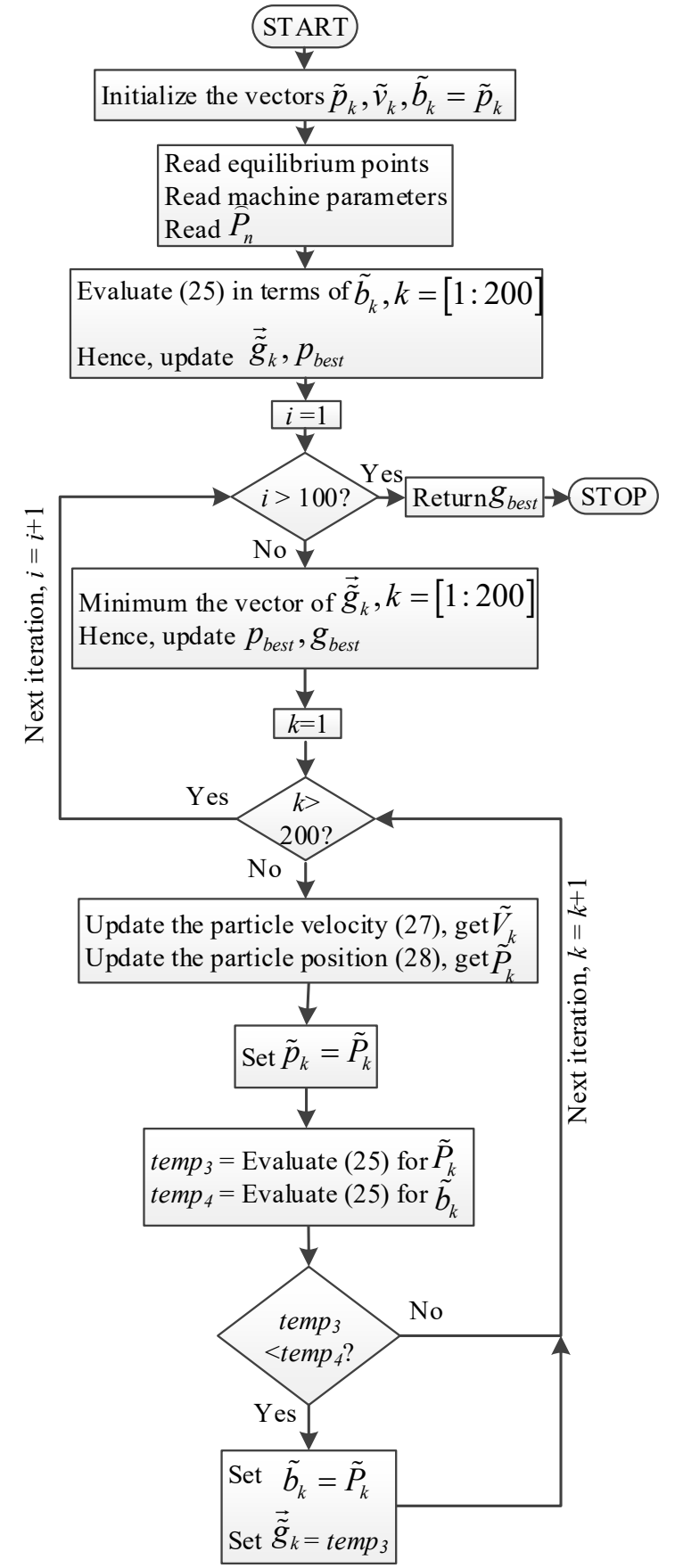

Fig. 6. Flowchart of the internal AVPSO algorithm.

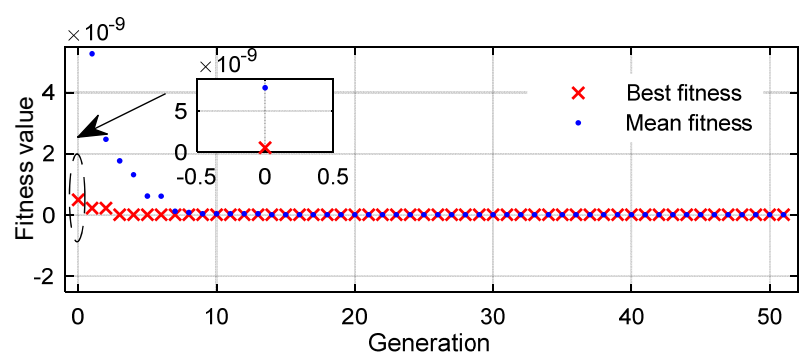

Fig. 7. Objective function evaluation.

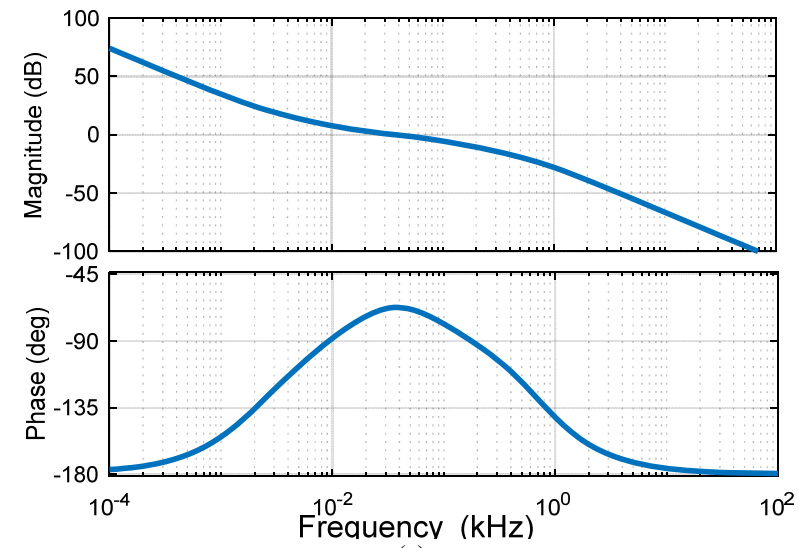

(a)
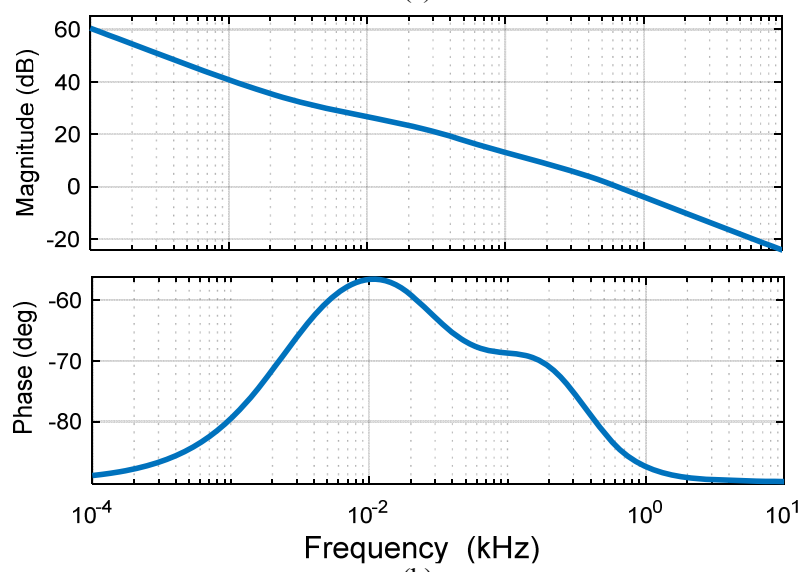

(b)

Fig. 8. Frequency response, where (a) speed controller bode plot, and (b) current controller bode plot.

Also, Fig. 9(a) presents the difference in dynamic performance between PFWC-SPIS and PFWC-AWS that is summarized in reduction the settling time from 1.3 to $0.56 \mathrm{~s}$, and in reducing the speed overshoot at the load drop period from $7 \%$ to $6 \%$, respectively. The average $q$-axis currents of both PFWC and CFWC are decreased from about 5.64 to 2.9 $\mathrm{A}$ at $2 \mathrm{~s}$ under the reduction of the motor torque as presented in Fig. 9(b). Fig. 9(c) presents the different of $d$-axis average currents that are -8.55 A for the PFWC with different PI structures and -6.5 A for the CFWC. Fig. 9(d) presents the unfiltered waveform of the voltage vector magnitude, which certainly proves that all control strategies involved in the fluxweakening region. The instantaneous magnitude of the voltage vector produces the maximum value. Further, Fig 9(d) defines the difference of the dc-bus voltage utilization under PFWC and CFWC strategies that are achieving average values of about 1 and 0.98 , respectively. Meanwhile, the average value of the line-modulation ratio under PFWC and CFWC are about 0.98 and 0.97, respectively, as illustrated in Fig. 9(e). Additionally, the magnitudes of duty cycles shown in Fig. 9(f) have the average values of about 1 and 0.98 , respectively, where the $D_{d q}$ is calculated for CFWC by $D_{d q}=\left(\sqrt{v_{d s}^{* 2}+v_{q s}^{* 2}}\right) / V_{d c}$. Lastly, the overall system efficiencies of the PFWC and the CFWC strategies from the 
dc-bus to mechanical output are $76.5 \%$ and $74.7 \%$ and then decreasing to about $45.3 \%$ and $44.85 \%$ after load drop, respectively.

Fig. 10 presents the dynamic simulation results of both flux weakening algorithms under the similar conditions used for Fig. 9, except for the motor parameters that are varying. These simulation results show what extent the algorithms depend on

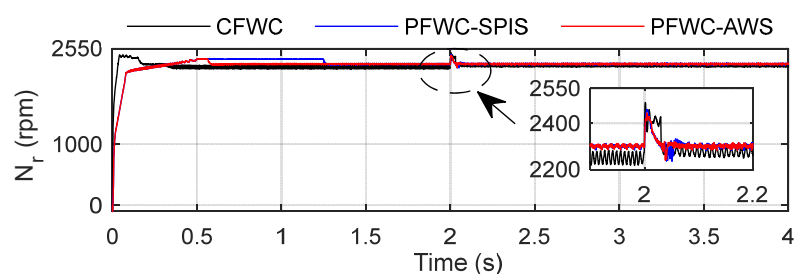

(a)

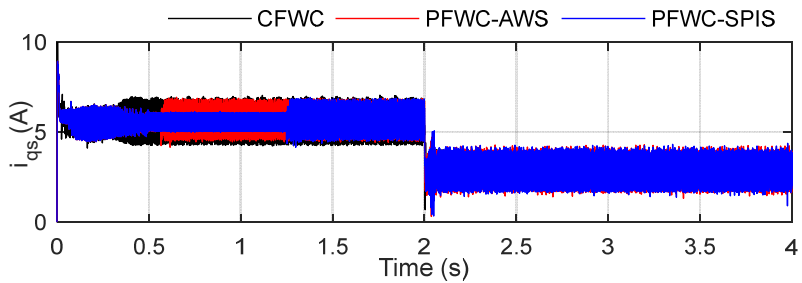

(b)

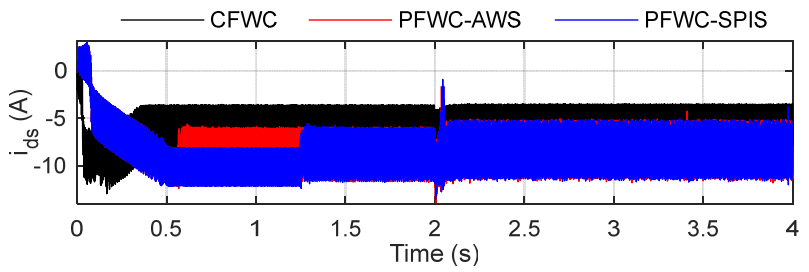

(c)

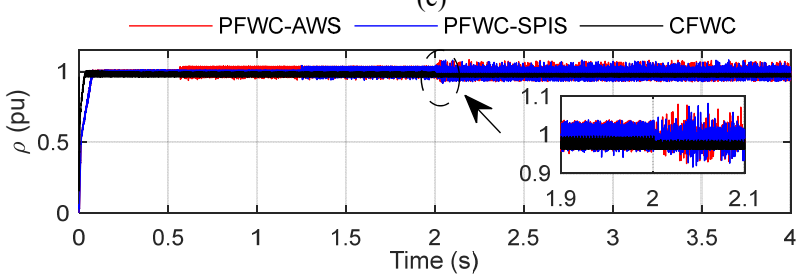

(d)

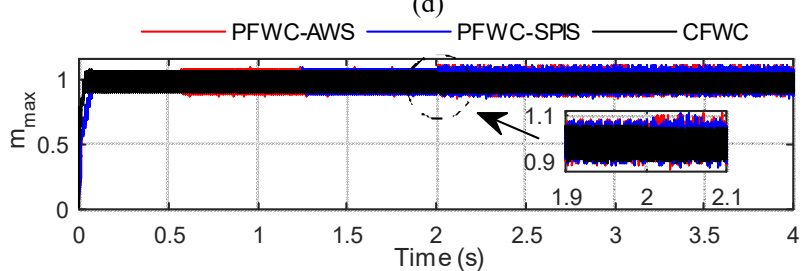

(e)

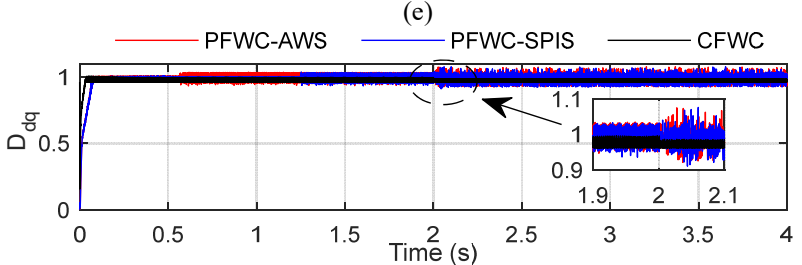

(f)

Fig. 9. Simulation results of PFWC and CFWC in case of motor torque reduction under the speed of $2300 \mathrm{rpm}$, where (a) motor speed, (b) q axis currents, (c) d-axis current, (d) magnitude of the voltage vector, (e) line modulation ratio, and (f) magnitude of the duty cycles. those parameters. The stator resistance is detuned from the nominal value to the value at the temperature of $122{ }^{\circ} \mathrm{C}$. Thus, the stator resistance is changed from 0.8 to $1.12 \Omega$, which can be determined by [25]

$$
R_{b}=\left(R_{a}\left(t_{b}+k_{1}\right)\right) /\left(t_{a}+k_{1}\right)
$$

where $R_{a}$ is the $R_{s}$ measured at the temperature $t_{a}=20^{\circ} \mathrm{C}, t_{b}$ is the temperature in ${ }^{\circ} \mathrm{C}$ to which the resistance is to be corrected, $k_{1}$ is about 234.5 for $100 \%$ conductivity copper, and $R_{b}$ is the winding resistance in $\Omega$ corrected to the temperature $t_{b}$ For the winding inductances, when the magnetic saturation occurs, the winding inductances would drop about $40 \%$ [26]. It can be concluded from Figs.10(a) and (b) that the speed and the $q$ axis current traces of the PFWC algorithm have fewer oscillations at steady-state than that of the CFWC algorithm.

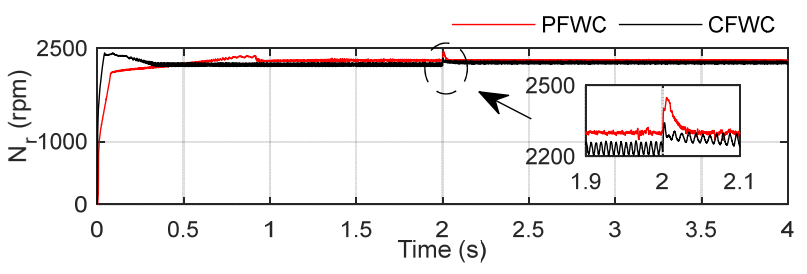

(a)

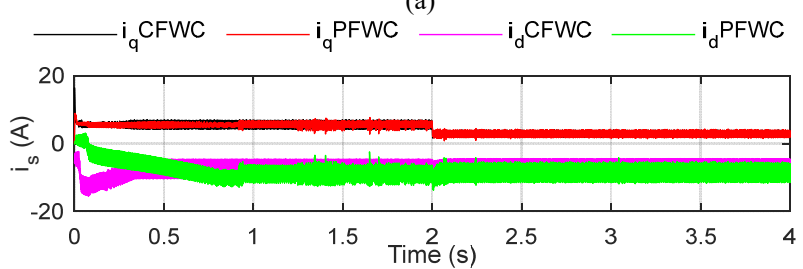

(b)

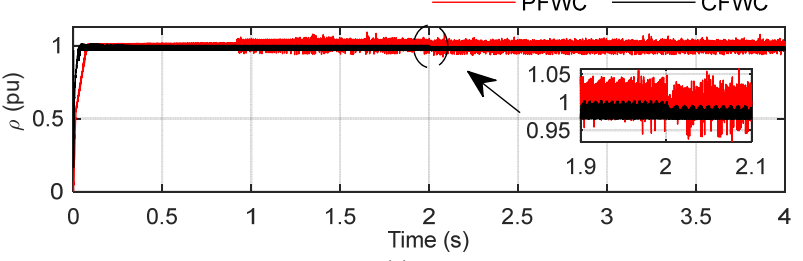

(c)

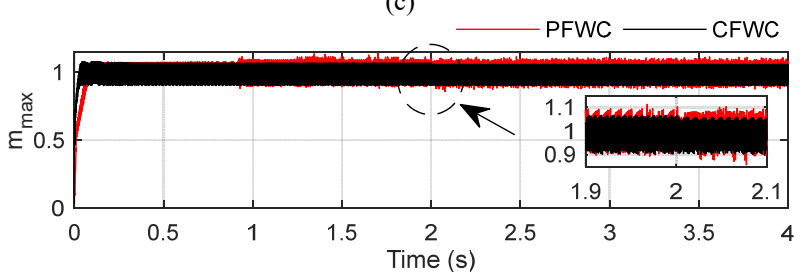

(d)

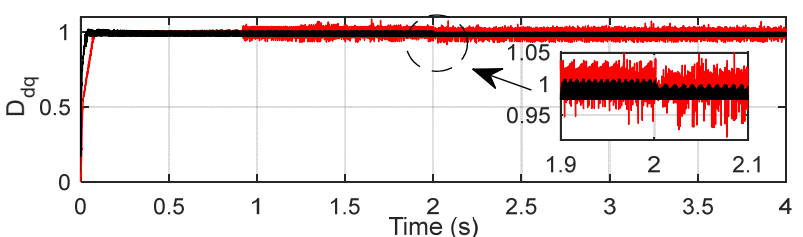

(e)

Fig. 10. Simulation results of PFWC and CFWC in case of parameters variation with load reduction under the speed of $2300 \mathrm{rpm}$, where (a) motor speed, (b) d-q axes currents, (c) magnitude of the voltage vector, (d) line modulation ratio, and (e) magnitude of the duty cycles. 
Comparing with the correctly tuned case in Fig. 9, the steadystate error value of the CFWC algorithm increases to about $3 \%$ and the counterpart of the PFWC algorithm is still less than $1 \%$. Both strategies seek to minimize the speed error under the parameter variation. As a result, the $d$-axis average currents of the PFWC and CFWC algorithms lightly decrease to about -8.7 and -7.5 A leading to an increase in the average value of the magnitudes of the duty cycles to about 1.01 and 0.986, respectively, as shown in Figs. 10(b) and (e). Fig. 10(c) presents that the per-unit magnitude of the unfiltered voltage vector under the CFWC algorithm is increased slightly to the average value of about 0.986 , and the counterpart under the PFWC algorithm is increased slightly to the average value of about 1.01. Furthermore, the averages of the line-modulation ratio value of the PFWC and CFWC algorithms are increased to about 0.99 and 0.98 , respectively, as depicted in Fig. 10(d). Moreover, the overall system efficiencies of the PFWC and CFWC algorithms are $76.4 \%$ and $74.2 \%$ and then decreased to about $44.8 \%$ and $44.2 \%$ after load drop, respectively.

\section{EXPERIMENTAL RESULTS}

This section proves the effectiveness of the proposed control algorithm considering the optimized parameters of AWPI controllers listed in Table III. Fig. 11 shows a photograph of the experimental test platform. This figure shows the test motor coupled with a $3-\mathrm{kW}$ interior magnet PMSM with an encoder of 4096 pulses per cycle. For this reason, the closed-loop torque mode control realizes the interior magnet PMSM as a load using field-oriented control. Moreover, the algorithms are implemented in the TMS320F28335 DSP board with C programing codes. The inputs for the control board are the dc-bus voltage regulated as $150 \mathrm{~V}$, the feedback signal of the encoder, and the measured phase currents. The sampling time of control loops is $100 \mu \mathrm{s}$. Tektronix oscilloscope with $1 \times$ passive voltage probe is used to measure signals. Measured signals have additional ripple due to the hardware noises. To verify the effectiveness of AWPI structure, Fig. 12 provides the dynamic performance under modified vector control, as shown in Fig. 3(c), for both structures based on the AWS and the SPIS. The reference speed is $500 \mathrm{rpm}$ that is increased to the maximum limit of the

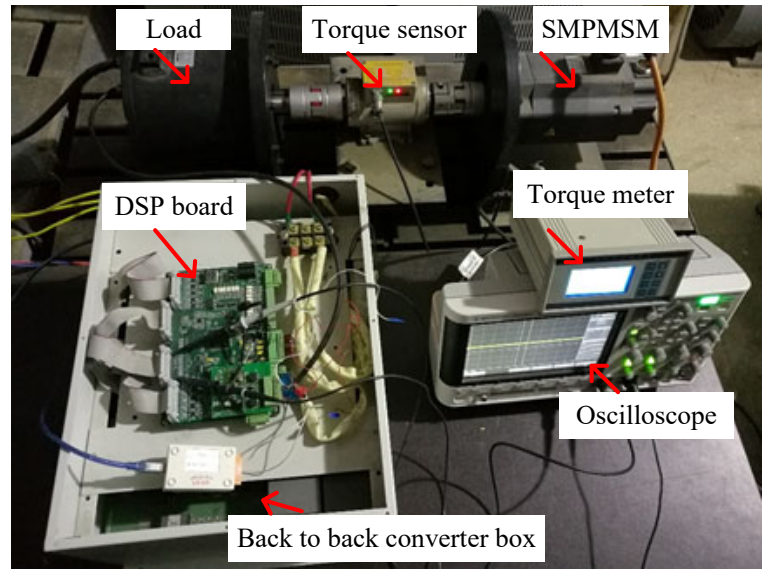

Fig. 11. The photograph of the experimental test platform.

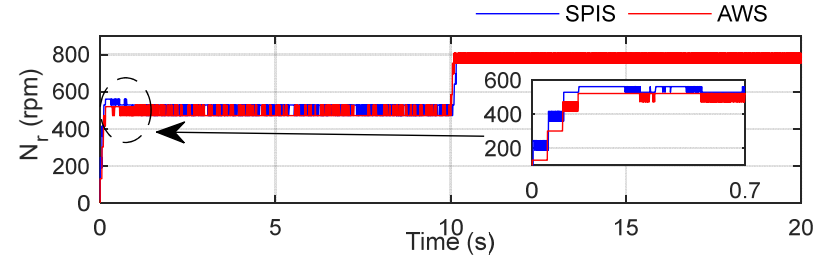

(a)

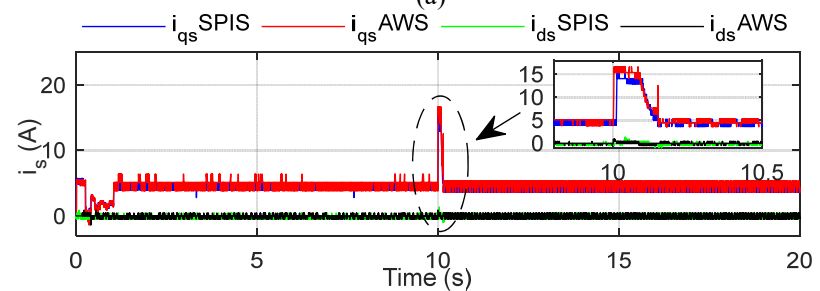

(b)

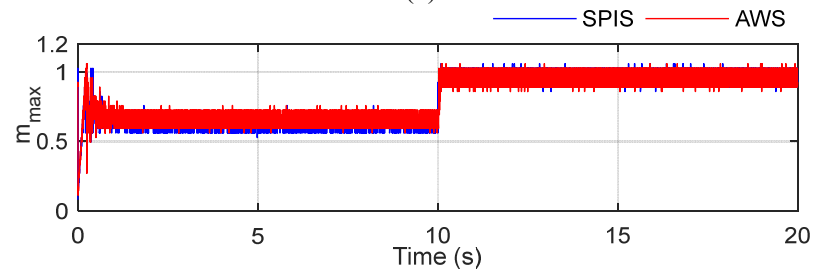

(c)

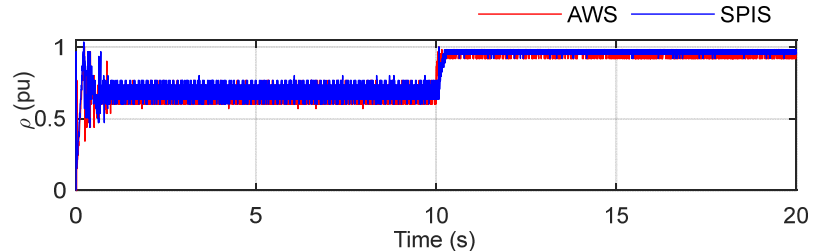

(d)

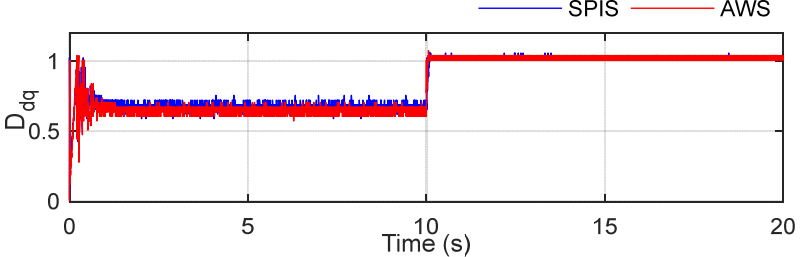

(e)

Fig. 12. Experimental results of the constant torque region case, where (a) speed, (b) d-q axes currents, (c) line modulation ratio, (d) magnitude of the voltage vector, and (e) magnitude of the duty cycles.

rotational speed at $10 \mathrm{~s}$ without using the flux weakening control loop $\left(i_{d s}^{*}=0\right)$, and the initial load torque is $7.5 \mathrm{Nm}$.

Fig. 12(a) shows the speed overshoot of SPIS with value $12 \%$, while the speed overshoot of AWS is $4 \%$. Meanwhile, the settling times are 0.76 and $0.15 \mathrm{~s}$, respectively. Besides, the averages of maximum rotational speed achieving in constant torque region are $780.7 \mathrm{rpm}$. The averages currents of $d-q$ axes are 0 and 4.5 A, respectively, as shown in Fig. 12(b). Fig. 12(c) explains the utilizing of the dc-bus voltage, where the average line modulation ratio increases from 0.64 to 0.94 . Meanwhile, Fig. 12(d) presents the voltage vectors under the constant torque region. Both structure cases increase average voltage vectors from 0.68 to 0.95 at $10 \mathrm{~s}$. Fig. 12(e) presents the magnitude of the duty cycles. The error between $D_{d q}$ and $D_{d q \max }^{*}$ will be the input of the proposed duty cycles regulating 
loop. Consequently, the AWPI regulator increases the negative of $d$-axis current to prevent the current controllers from the saturation.

Fig. 13 presents the limit of the maximum speed of PFWC and CFWC at the flux-weakening region with initial load torque of $7.5 \mathrm{Nm}$. In this case, the speed programmed in a ramp function reverses the direction at the time of $50 \mathrm{~s}$ to ensure the four-quadrant operation of the driving algorithm, which includes the transition between the constant torque and the flux weakening regions. As shown in Fig. 13(a), the speed change of PFWC within the constant torque and a fluxweakening fields is faster than that of CFWC in the reverse direction. Furthermore, the PFWC involves in a higher speed

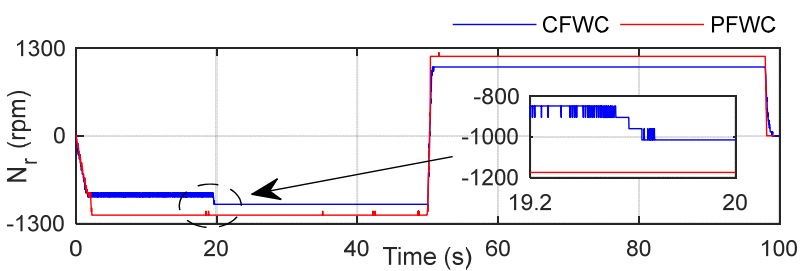

(a)

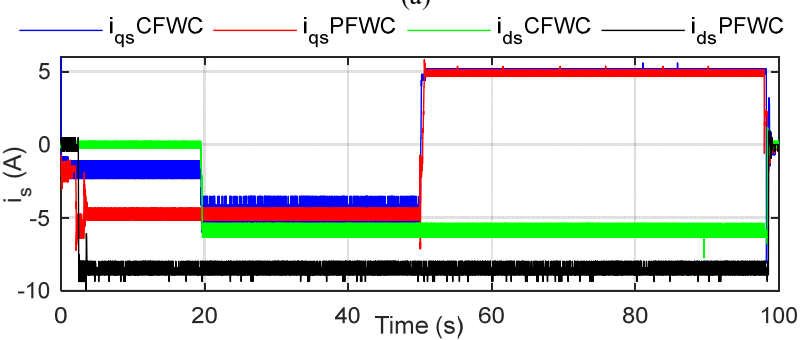

(b)

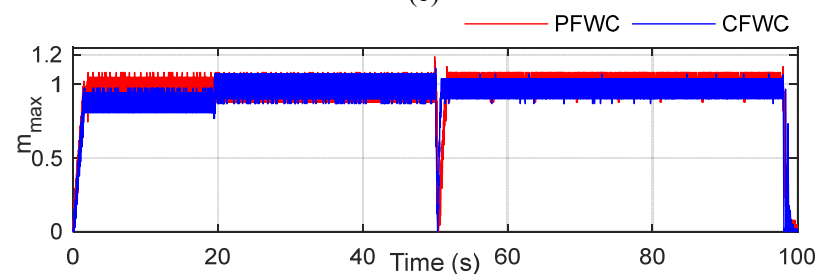

(c)

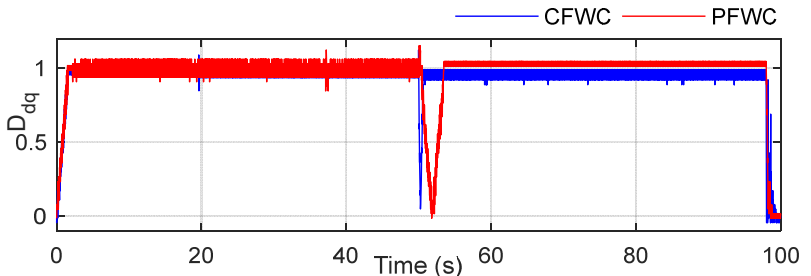

(d)

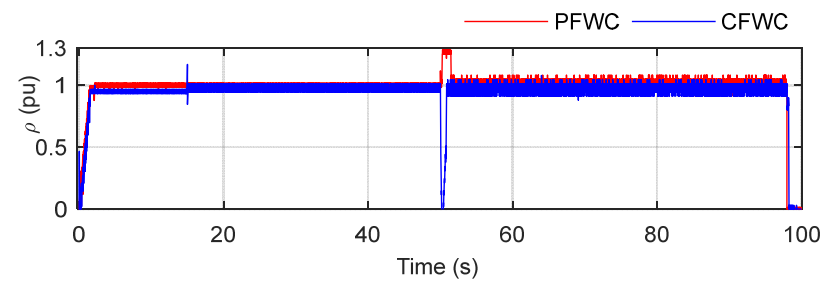

(e)

Fig. 13. Experimentally measured results of the reversing direction case, where (a) motor speed, (b) d-q axes currents, (c) line modulation ratio, (d) magnitude of the duty cycles, and (e) magnitude of the voltage vector. than the CFWC with the values of about 1175 and $1016 \mathrm{rpm}$, respectively. Fig. 13(e) presents that the voltage vectors under the flux-weakening region are laying on the boundary of the maximum voltage that the inverter can supply to the motor preventing the speed from breaking these limits under the operating conditions. The average voltage vector magnitude under PFWC and CFWC are 1 and 0.986, respectively. Both PFWC and CFWC increase average $q$-axis currents from -4.76 to $5 \mathrm{~A}$ at $50 \mathrm{~s}$, as shown in Fig. 13(b). However, they produce different $d$-axis currents. As shown in this figure, the $d$-axis average current of PFWC is about -8.45 A. Similarly, the $d$ axis average current of CFWC is about $-5.87 \mathrm{~A}$. The reason is

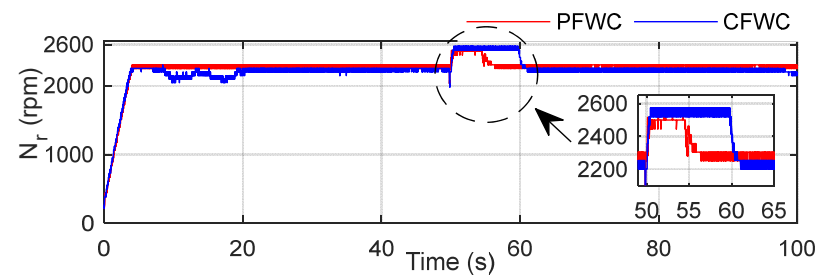

(a)

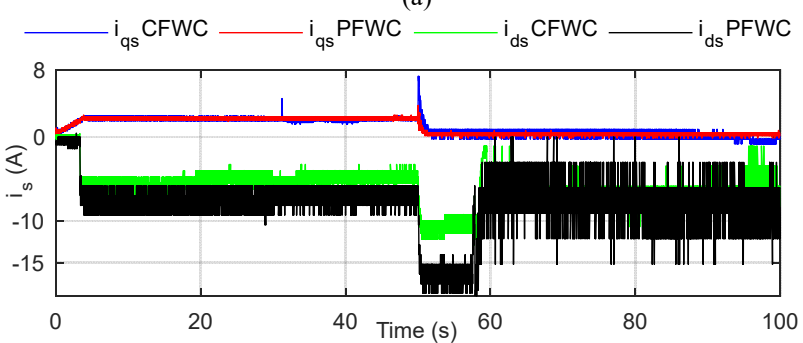

(b)

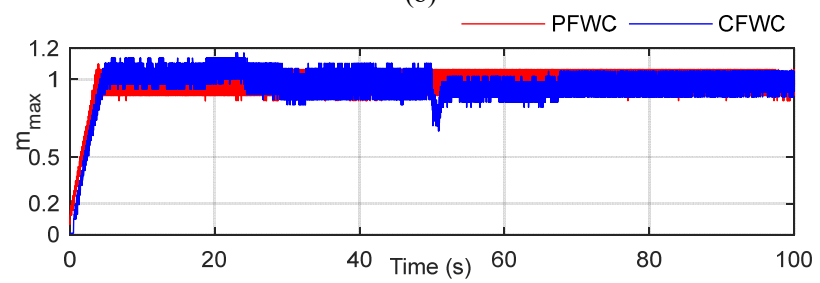

(c)

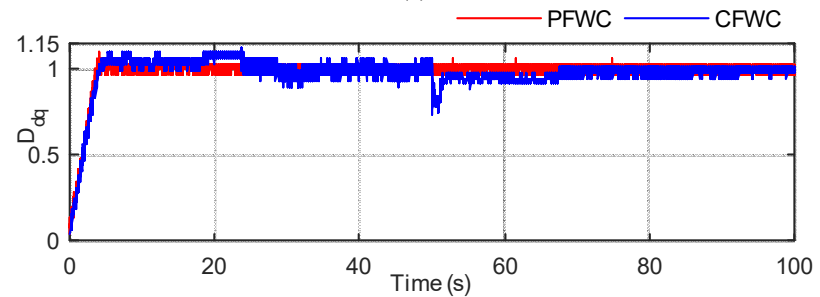

(d)

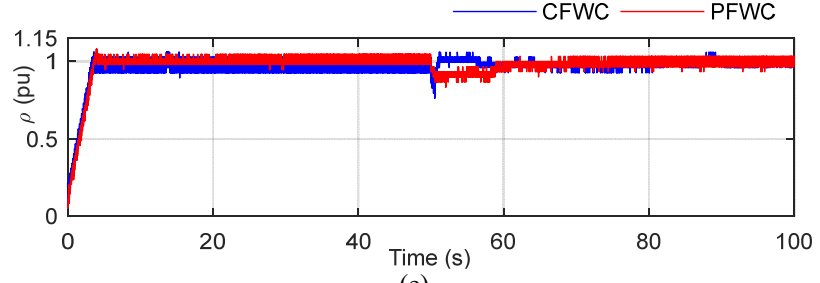

(e)

Fig. 14. Experimentally measured results of the load torque reduction case, where (a) motor speed, (b) d-q axes currents, (c) line modulation ratio, (d) magnitude of the duty cycles, and (e) magnitude of the voltage vector. 
that both PFWC and CFWC have different average linemodulation ratios of 0.98 and 0.97 , respectively, as presented in Fig. 13(c). Meanwhile, the average duty cycle magnitude given in Fig. 13(d) under PFWC and CFWC are 1 and 0.95, respectively. The control in the flux-weakening region under the unrated torque decreases the overall efficiencies of PFWC and CFWC to about $72.9 \%$ and $72.2 \%$, respectively.

Fig. 14 shows the dynamic performance of PFWC and CFWC running the SMPMSM at the flux-weakening region with a reference speed of $2300 \mathrm{rpm}$ and a load torque variation from 3.5 to $0.5 \mathrm{Nm}$ at $50 \mathrm{~s}$. The dc-bus voltage is increased to $400 \mathrm{~V}$ to break the speed limit of the previous case shown in Fig. 13. While suddenly reducing the load torque, the PFWC has a small transient period to keep the reference rotational speed at the flux-weakening region better than that of CFWC as presented in Fig. 14(a). Moreover, the steady-state error of PFWC is better than that of CFWC with the value of about $1 \%$ and $3.2 \%$ for PFWC and CFWC, respectively. High oscillation wave attaches the average of $q$-axis current wave under CFWC as shown in Fig. 14(b). Both PFWC and CFWC decrease the average $q$-axis currents from 2.22 to $0.32 \mathrm{~A}$ at the load torque reduction time. Additionally, the average value of $d$-axis current under PFWC is about -7.6 A, and that value under CFWC reaches $-5.9 \mathrm{~A}$. Besides, the average values of the line-modulation ratio under both PFWC and CFWC are about 0.98 and 0.97, respectively, as provided in Fig. 14(c). Meanwhile, those of the magnitude of duty cycles, as shown in Fig. 14(d), are about 1 and 0.98 , respectively. The overall efficiencies of the PFWC and the CFWC algorithms are $71.8 \%$ and $71.5 \%$, respectively. The appearance of the voltage vector at the boundary of the maximum voltage limit confirms that the motor speed has been involved in the flux-weakening region as presented in Fig. 14(e). The average voltage vector magnitude under PFWC and CFWC are 1 and 0.98, respectively.

\section{CONCLUSION}

This paper presents parameter optimization of the improved vector control scheme to control an SMPMSM in the flux weakening region. The anti-windup structure which improves the dynamic performance of the vector control strategy employs the full saturated output of the PI controllers to defeat the overshoot effect of saturation. The novelty of the parameter tuning method relies on adopting the equilibrium point term of Taylor series as the proposed objective function. Thus, the proposed adaptive velocity PSO algorithm optimizes the objective function looking for the optimal parameter to achieve the minimum error for the controllers. Meanwhile, the control strategy utilizes the compensated duty cycles to determine the outbreak of the field weakening point.

The theoretical study with the simulation and the experiment results of the PFWC demonstrate parameters robustness that proves the success of the proposed tuning method. Further, the results confirm the success of the AWPI structure in the reduction of the overshoot impact during the transient process. Besides, this control strategy decides the flux weakening point, and then the negative $d$-axis current is injected which results in an additional voltage to control the motor in field decreasing region. Simulation results verify that the proposed flux weakening method has little dependence on the machine parameters. From the experimental results, the proposed algorithm significantly increases the maximum speed limit of constant torque region, which demonstrates that the dc-link voltage utilization for the proposed controller is better than that for CFWC. Meanwhile, the proposed flux weakening control loop introduces a fast and stable transfer within a field decreasing region.

\section{REFERENCES}

[1] K. Putri, M. Hombitzer, D. Franck, and K. Hameyer, "Comparison of the characteristics of cost-oriented designed high-speed low-power interior PMSM," IEEE Trans. Ind. Appl., vol. 53, no. 6, pp. 5262-5271, Dec. 2017.

[2] S.-K. Sul, Control of electric machine drive systems. John Wiley \& Sons, 2011.

[3] B. Du, S. Wu, S. Han, and S. Cui, "Interturn fault diagnosis strategy for interior permanent-magnet synchronous motor of electric vehicles based on digital signal processor," IEEE Trans. Ind. Electron., vol. 63, no. 3, pp. 1694-1706, Mar. 2016.

[4] X. Liu, H. Chen, J. Zhao, and A. Belahcen, "Research on the performances and parameters of interior PMSM used for electric vehicles," IEEE Trans. Ind. Electron., vol. 63, no. 6, pp. 3533-3545, June 2016

[5] J. Lopez-Sanz et al., "Thermal management in plug-in hybrid electric vehicles: a real-time nonlinear model predictive control implementation," IEEE Trans. Veh. Technol., vol. 66, no. 9, pp. 77517760, Sept. 2017.

[6] J. Mun, G. Park, S. Seo, D. kim, Y. Kim, and S. Jung, "Design characteristics of IPMSM with wide constant power speed range for ev traction," IEEE Trans. Magn., vol. 53, no. 6, pp. 1-4, June 2017.

[7] W. Tang and Y. J. Zhang, "A model predictive control approach for low-complexity electric vehicle charging scheduling: optimality and scalability," IEEE Trans. Power Syst., vol. 32, no. 2, pp. 1050-1063, Mar. 2017.

[8] Y. Chen et al., "Improved flux-weakening control of IPMSMs based on torque feedforward technique," IEEE Trans. Power Electron., vol. 33, no. 12 , pp. 10970-10978, Dec. 2018.

[9] K. Kim, "A novel magnetic flux weakening method of permanent magnet synchronous motor for electric vehicles," IEEE Trans. Magn., vol. 48, no. 11, pp. 4042-4045, Nov. 2012.

[10] Z. Li, Y. Li, and X. Li, "Flux control of a CPPM machine for both a wide speed range and high efficiency," IEEE Trans. Power Electron., vol. 29, no. 9, pp. 4866-4876, Sept. 2014.

[11] H. Liu, Z. Q. Zhu, E. Mohamed, Y. Fu, and X. Qi, "Flux-weakening control of nonsalient pole PMSM having large winding inductance, accounting for resistive voltage drop and inverter nonlinearities," IEEE Trans. Power Electron., vol. 27, no. 2, pp. 942-952, Feb. 2012.

[12] J. Liu, C. Gong, Z. Han, and H. Yu, "IPMSM model predictive control in flux-weakening operation using an improved algorithm," IEEE Trans. Ind. Electron., vol. 65, no. 12, pp. 9378-9387, Dec. 2018.

[13] Y. Liu, J. Zhao, R. Wang, and C. Huang, "Performance improvement of induction motor current controllers in field-weakening region for electric vehicles," IEEE Trans. Power Electron., vol. 28, no. 5, pp. 2468-2482, May 2013.

[14] Z. Mynar, L. Vesely, and P. Vaclavek, "PMSM model predictive control with field-weakening implementation," IEEE Trans. Ind. Electron., vol. 63, no. 8, pp. 5156-5166, Aug. 2016.

[15] P. Sandulescu, F. Meinguet, X. Kestelyn, E. Semail, and A. Bruyère, "Control strategies for open-end winding drives operating in the fluxweakening region," IEEE Trans. Power Electron., vol. 29, no. 9, pp. 4829-4842, Sept. 2014

[16] L. Sepulchre, M. Fadel, M. Pietrzak-David, and G. Porte, "MTPV fluxweakening strategy for PMSM high speed drive," IEEE Trans. Ind. Appl., vol. 54, no. 6, pp. 6081-6089, Dec. 2018. 
[17] M. Tursini, E. Chiricozzi, and R. Petrella, "Feedforward flux-weakening control of surface-mounted permanent-magnet synchronous motors accounting for resistive voltage drop," IEEE Trans. Ind. Electron., vol. 57, no. 1, pp. 440-448, Jan. 2010.

[18] W. Wang, J. Zhang, and M. Cheng, "Line-modulation-based fluxweakening control for permanent-magnet synchronous machines," IET Power Electron., vol. 11, no. 5, pp. 930-936, Mar. 2018.

[19] Z. Zhang, C. Wang, M. Zhou, and X. You, "Flux-weakening in PMSM drives: analysis of voltage angle control and the single current controller design," IEEE J. Emerg. Sel. Topics in Power Electronics, pp. 1-1, May 2018.

[20] Y. Jiang, W. Xu, C. Mu, and Y. Liu, "Improved deadbeat predictive current control combined sliding mode strategy for PMSM drive system," IEEE Trans. Veh. Technol., vol. 67, no. 1, pp. 251-263, Jan. 2018.

[21] M. H. Vafaie, B. M. Dehkordi, P. Moallem, and A. Kiyoumarsi, "Improving the steady-state and transient-state performances of PMSM through an advanced deadbeat direct torque and flux control system," IEEE Trans. Power Electron., vol. 32, no. 4, pp. 2964-2975, Apr. 2017.

[22] W. Xu, Y. Jiang, and C. Mu, "Novel composite sliding mode control for PMSM drive system based on disturbance observer," IEEE Trans. on Appl. Supercond., vol. 26, no. 7, pp. 1-5, Oct. 2016.

[23] W. Wang, M. Cheng, B. Zhang, Y. Zhu, and S. Ding, "A Fault-tolerant permanent-magnet traction module for subway applications," IEEE Trans. Power Electron., vol. 29, no. 4, pp. 1646-1658, Apr. 2014.

[24] N. Pragallapati, T. Sen, and V. Agarwal, "Adaptive velocity PSO for global maximum power control of a PV array under nonuniform irradiation conditions," IEEE J. Photovolt., vol. 7, no. 2, pp. 624-639, Mar. 2017.

[25] IEEE, "IEEE standard test procedure for polyphase induction motors and generators," ed: IEEE Standards Project Editor New York, Nov. 2004 .

[26] G. Feng, C. Lai, and N. C. Kar, "A novel current injection-based online parameter estimation method for PMSMs considering magnetic saturation," IEEE Trans. Magn., vol. 52, no. 7, pp. 1-4, July 2016.

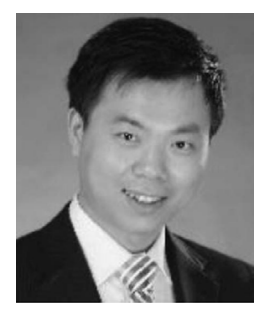

Wei Xu (M'09-SM'13) received the double B.E. and M.E. degrees from Tianjin University, Tianjin, China in 2002 and 2005, and the Ph.D. from the Institute of Electrical Engineering, Chinese Academy of Sciences, in 2008, respectively, all in electrical engineering.

From 2008 to 2012, he held several academic positions in both Australian and Japanese universities and companies. Since 2013, he has been full professor with the State Key Laboratory of Advanced Electromagnetic Engineering and Technology, Huazhong University of Science and Technology, China. His research topics mainly cover design and control of linear/rotary machines. He is Fellow of the Institute of Engineering and Technology (IET). He has served as Associate Editor for several Journals, such as IEEE Transactions on Industrial Electronics, IEEE Journal of Emerging and Selected Topics in Power Electronics, IEEE Transactions on Vehicular Technology, etc.

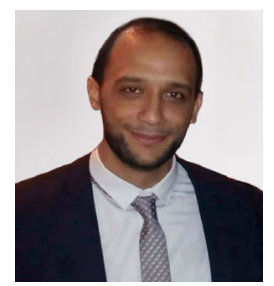

Moustafa Magdi Ismail received the B.Sc. and M.Sc. degree in the school of Electrical Engineering, Minia University, Minia, Egypt, in 2011 and 2016, respectively. He was appointed an Assistant Lecturer in the School of Electrical Engineering, Minia University from Oct. 2011 to Sept. 2017. From Sept. 2017, he has been pursuing the Ph.D. degree at the State Key Laboratory of Advanced Electromagnetic Engineering and Technology, School of Electrical and Electronic Engineering, Huazhong University of Science and Technology, Wuhan, China.

His current research interests include advanced control of electrical drives, power converter systems, smart grid, and optimization algorithms.

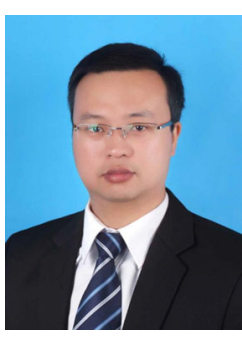

Yi Liu (M'14) received his B.E. and M.E. degrees in Automation and Control Engineering from the Wuhan University of Science and Technology, Wuhan, China, in 2004 and 2007, respectively; and his Ph.D. degree in Mechatronic Engineering from the Huazhong University of Science and Technology, Wuhan, China, in 2016.

From 2007 to 2011, he was a Lecturer at the City College, Wuhan University of Science and Technology, Wuhan, China. From March 2016 to June 2016, he was a Senior R \& D Engineer at the Fourth Academy of China Aerospace Science and Industry Group, Wuhan, China. In July 2016, he became a Postdoctoral Research Fellow at the State Key Laboratory of Advanced Electromagnetic Engineering and Technology, School of Electrical and Electronic Engineering, Huazhong University of Science and Technology.

His current research interests include AC electrical machine control and inverter systems.

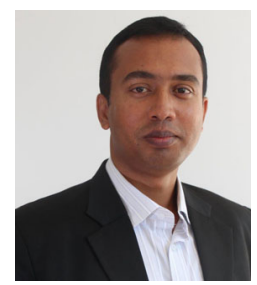

Md. Rabiul Islam (M'14-SM'16) received the B.Sc. and M.Sc. degree from Rajshahi University of Engineering and Technology (RUET), Rajshahi, Bangladesh, in 2003 and 2009, respectively; and the $\mathrm{Ph} . \mathrm{D}$. degree from University of Technology Sydney (UTS), Sydney, Australia, in 2014, all in electrical engineering.

He was appointed a lecturer at RUET in 2005 and promoted to full professor in 2017. In early 2018, he joined at the School of Electrical, Computer, and Telecommunications Engineering (SECTE), University of Wollongong (UOW), Wollongong, Australia. He is also a member of Australian Power Quality and Reliability Center of UOW. From 2013 to 2014, he was a Research Associate with UTS. His research interests are in the fields of power electronic converters, renewable energy technologies, power quality, electrical machines, and smart grid. He has served as a Guest Editor for IEEE Transactions on Energy Conversion and IEEE Transactions on Applied superconductivity. Currently he is editing a special issue for IET Electric Power Applications. 